\title{
Investigation of the sorption properties of carbon nanotubes with different boron impurity contents
}

\author{
S. V. Boroznin, I. V. Zaporotskova, N. P. Polikarpova \\ Volgograd State University, Volgograd, Russia \\ sboroznin@mail.ru,n.z.1103@mail.ru, irinazaporotskova@gmail.com
}

PACS 61.48.De

DOI 10.17586/2220-8054-2016-7-1-93-98

\begin{abstract}
Since their discovery in the early 1990's, carbon nanotubes (CNTs) have become the subject of numerous investigations into their electronic structure and energy spectrum parameters as well as their physico-chemical properties. Due to their high surface activity, nanotubes can be used as base components for the fabrication of various types of composites. However, along with carbon nanotubes, current research also focuses on theoretical and experimental investigation of non-carbon nanotubes, namely recently discovered boron-carbon nanotubes with different concentrations of boron in them ( $25 \%$ or $50 \%$ ). This article presents the results of theoretical research into the properties of boron-carbon nanotubes (BCNTs) within the framework of an ionic-built covalent-cyclic cluster model and an appropriately modified MNDO quantum chemical scheme, as well as DFT method. The authors studied mechanism of $\mathrm{Cl}$ and $\mathrm{O}$ atoms sorption onto the external surface of single-walled armchair nanotubes. As result of the study, geometrical optimization of the sorption complexes was defined, and sorption energy values were obtained.
\end{abstract}

Keywords: nanotechnologies, boron-carbon nanotubes, sorption properties.

Received: 20 November 2015

\section{Introduction}

Since their discovery in the early 1990's, carbon nanotubes (CNTs) have become the subject of numerous investigations into their electronic structure and energy spectrum parameters as well as their physico-chemical properties. Along with studies of nanotube properties researchers have begun to search for ways to modify NTs and fabricate structures that could possess new mechanical, electronic and other properties. Due to their high surface activity, nanotubes can be used as a base component for the fabrication of various types of composites. In particular, it was found out that pure carbon nanotubes might be used for gas storage because of their excellent adsorption properties [1-3].

As the properties of pure carbon nanotubes are well known, the researchers decided to investigate other types of the nanotube-based structures. One of the most useful type of nanotubes is one based on boron carbide. Earlier studies have shown that the physical and chemical properties of boron-carbon nanotubes (BCNT) are better than those of the corresponding CNTs [4-8].

The nanotube's adsorption process attracts the attention of our research group as well as other researchers around the world [9-13]. The calculations for the adsorption processes of the oxygen atom and $\mathrm{O}_{2}$ molecule on the surface of $\mathrm{BC}_{3}$ zig-zag nanotubes have been performed previously [14].

\section{Oxygen adsorption on the surface of BCNT}

The possibility of interaction between an oxygen atom and the external surfaces of $\mathrm{A}$ and $\mathrm{B}$ type $\mathrm{BC}_{3}$ nanotubes was studied. The calculations were carried out using a molecular cluster model with the semi-empirical MNDO scheme. As a cluster model of a boron carbon 
nanotube, a fragment that consisted of 30 atoms of boron and 90 atoms of carbon for A type, and 84 atoms of carbon and 36 atoms of boron for B type were chosen. There are four hexagon layers along the nanotube axis, and twelve boron carbon hexagons on its perimeter. The borders of the nanotube are isolated with pseudo atoms - hydrogen atoms. Length of bonds $\mathrm{B}-\mathrm{C}, \mathrm{C}-\mathrm{C}$ and B-B totaled $1.44 \AA$.

The different adatom orientations were simulated: for A type 1) above the boron atom, 2) above the carbon atom, 3) above the $\mathrm{B}-\mathrm{C}$ bond, 4) above the $\mathrm{C}-\mathrm{C}$ bond, 5) above the hexagon center, 6) above the B-B bond (see Fig. 1).
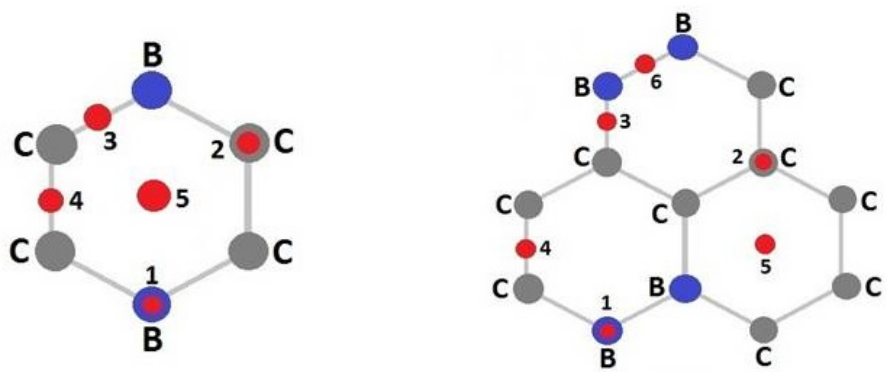

FIG. 1. The different types of adatom orientation were simulated: for A type 1) above the boron atom, 2) above the carbon atom, 3) above the $\mathrm{B}-\mathrm{C}$ bond, 4) above the $\mathrm{C}-\mathrm{C}$ bond, 5) above the hexagon center, 6) above the $\mathrm{B}-\mathrm{B}$ bond

In the first and second types of orientation, the oxygen atom approaches the surface of $\mathrm{B}$ or $\mathrm{C}$ atoms that are located in the center of the molecular cluster of boron carbon nanotube in order to avoid the influence of edge effects. The boron-carbon nanotube fragment with adsorbed oxygen atom is shown in Fig. 2. The adsorption process was simulated by an oxygen atom in a step-wise approach to the nanotube surface with $0.1 \AA$ increments perpendicular to the axis of the nanotube. The geometry of the system was optimized at each step. The calculations allow one to generate potential energy curves for each type of nanotube (see Figs. 3 and 4). Analysis of the energy curve shows that the oxygen atom is adsorbed onto the nanotube's surface. The minimum on the energy curve proves the fact of adsorption. The type of the bond between the adsorbed atom and the carbon atom of the nanotube surface is chemical. Therefore, the type of adsorption is chemical. The basic characteristics of these processes are shown in Tables 1 and 2. The location of oxygen atom above the $\mathrm{B}-\mathrm{C}$ for $\mathrm{A}$ type and $\mathrm{B}-\mathrm{B}$ bond for $\mathrm{B}$ type is energetically favorable. Geometrical analysis shows that the approaching of the oxygen atom causes a surface deformation for the A type BCNTs. The boron and carbon atoms leave their usual location and approach the adsorbed atom. The chemical bond between oxygen atom and nanotube surface occurs at a distance of $1.3 \AA$ from the nanotube surface by means of so-called 'bridge structure'. Geometrical analysis of B type boron carbon nanotube shows that there is no adsorption above B-B bond at a distance of $3 \AA$. Further approach causes boron atoms to leave their location: one boron atom penetrates $0.2 \AA$ inside the nanotube, and the other one approaches the adsorbed atom by $0.4 \AA$. The oxygen atom bonds with boron atom at a distance of $1.5 \AA$, and then this complex moves $0.5 \AA$ into the nanotube.

The adsorption processes for other types of adsorbed atoms were simulated in the same manner. The oxygen atom approached the fictive atom located above $\mathrm{B}-\mathrm{C}, \mathrm{B}-\mathrm{B}, \mathrm{C}-\mathrm{C}$ bonds or above the hexagon center. The chemical adsorption for these variants is possible, and the energy curves have similar trends (see Figs. 3 and 4). The basic characteristics of the adsorption processes are shown in Tables 1 and 2. 


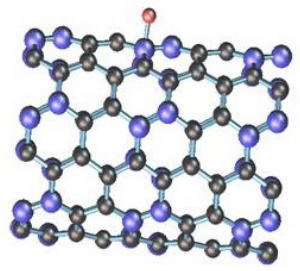

Type A

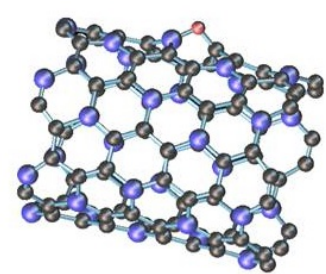

Type B

FIG. 2. Fragment of boron-carbon nanotube $(6,6)$ A and B type with adsorbed oxygen atoms

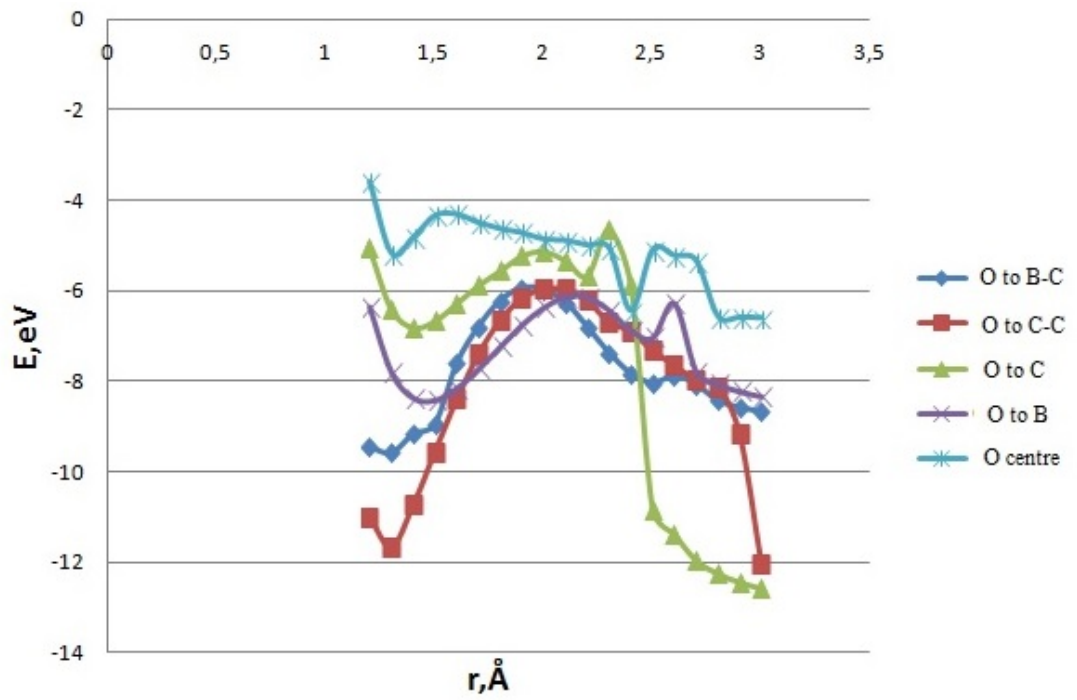

FIG. 3. Potential energy curve of the interaction between oxygen atom and the A type $(6,6)$ BCNT surface for all oxygen atom locations

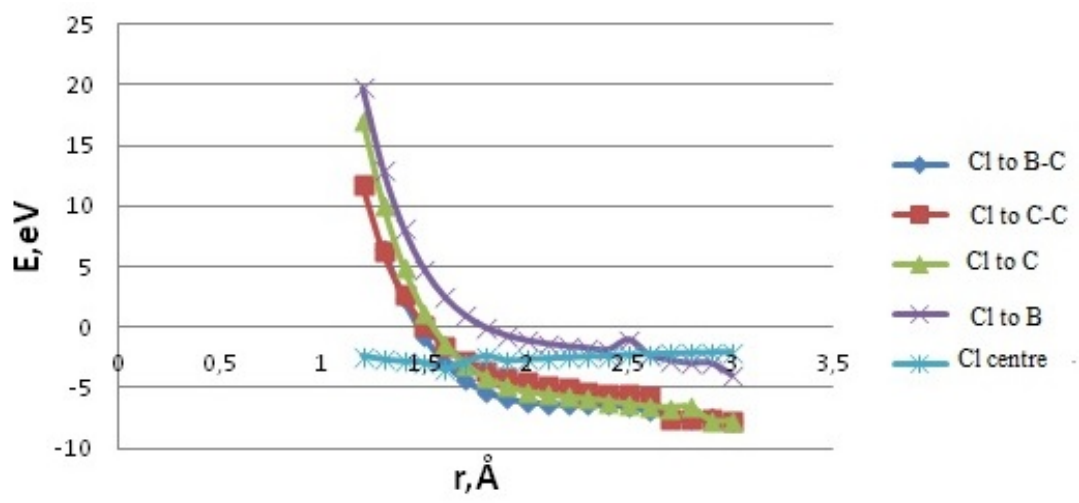

FIG. 4. Potential energy curve of the interaction between oxygen atom and the B type $(6,6)$ BCNT surface for all oxygen atom locations 
TABLE 1. Basic electron energy characteristics of oxygen adsorption process on the A type BCNT surface

\begin{tabular}{|c|c|c|c|}
\hline $\begin{array}{c}\text { Variant of } \\
\text { adsorption }\end{array}$ & Activation energy & Adsorption distance & Adsorption energy \\
\hline B-B & - & - & - \\
\hline B-C & 2.07 & 1.3 & -9.56 \\
\hline C-C & 6.09 & 1.3 & -11.66 \\
\hline C & 7.94 & 2.2 & -5.67 \\
\hline B & 0.89 & 1.5 & -8.4 \\
\hline To center & 2.15 & 2.4 & -6.44 \\
\hline
\end{tabular}

TABLE 2. Basic electron energy characteristics of the oxygen adsorption process on the B type BCNT surface

\begin{tabular}{|c|c|c|c|}
\hline $\begin{array}{c}\text { Variant of } \\
\text { adsorption }\end{array}$ & Activation energy & Adsorption distance & Adsorption energy \\
\hline B-B & - & 1.3 & -11.69 \\
\hline B-C & 2.3 & 1.3 & -9.63 \\
\hline C-C & - & 1.3 & -11.51 \\
\hline C & 1.85 & 1.4 & -6.62 \\
\hline B & - & 1.4 & -9.54 \\
\hline To center & 3.74 & 2.2 & -6.06 \\
\hline
\end{tabular}

\section{Chlorine adsorption on the surface of BCNT}

The possibility of chlorine adsorption on the external surface of A and B type BCNTs was investigated in the same manner as the oxygen atom. The calculations were made using molecular cluster model with the semi-empirical MNDO scheme. The approaching of the chlorine atom and variants of adsorption were simulated in the same way as for the oxygen atom.

The calculations generated potential energy curves for chlorine adsorption onto the surface of a BCNT.

Analysis of the energy curves shows that there is no adsorption of the chlorine atom onto the external surface of the BCNT (Fig. 5). There are two types of adsorption for the chosen atom: above the hexagon center for nanotube A type, and above the B-B bond for B type (Fig. 6). This type of adsorption is physical.

Geometrical analysis of the system shows that the interaction between chlorine atom and the nanotube surface begins at a distance of $2.5 \AA$ (Fig. 7). Both boron atoms approach the chlorine atom. The chlorine atom moves to one of the boron atoms. The chemical bond between them occurs at a distance of $1.9 \AA$. Then, the boron atoms return to their initial location. The length of the chlorine-boron bond is $1.2 \AA$. Therefore, chlorine adsorption does not cause nanotube deformation.

The optimal adsorption distance and activation energy are represented in the Table 3. 


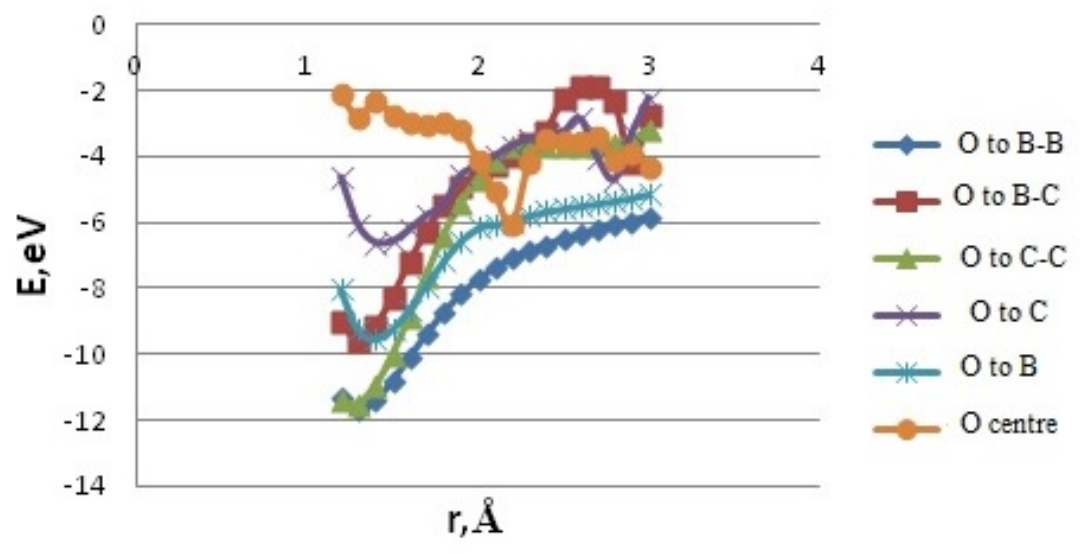

FIG. 5. Potential energy curve for the interaction between chlorine atom and the A type $(6,6)$ BCNT surface for all chlorine atom locations

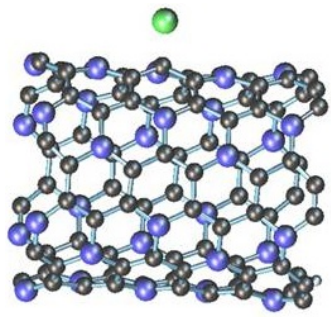

Type A

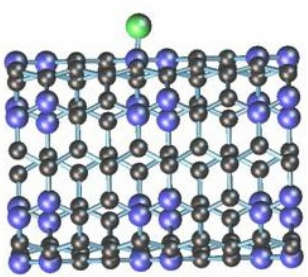

Type B

Fig. 6. Fragment of A and B type $(6,6)$ BCNT with adsorbed chlorine atoms

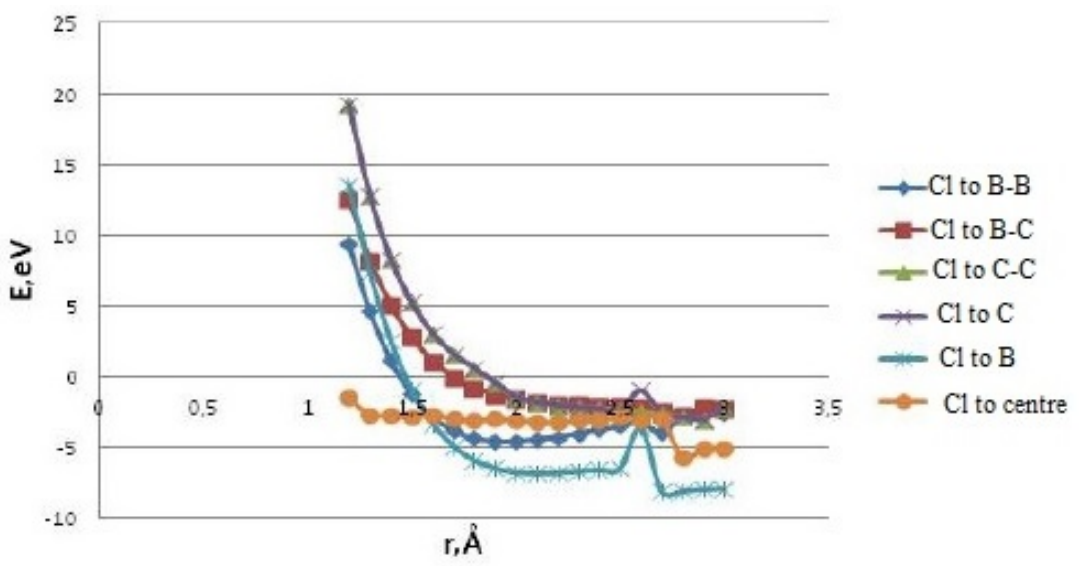

FIG. 7. Potential energy curve for the interaction between a chlorine atom and the B type $(6,6)$ BCNT surface for all chlorine atom locations

\section{Conclusion}

The MNDO calculations for the adsorption of chlorine and oxygen atoms onto the BCNT surface were carried out. The most energetically favorable mechanisms for these processes were determined.

Oxygen and chlorine atoms were adsorbed onto the BCNT surface. It was determined that these processes depended on the orientations of atoms surface. 
TABLE 3. Basic electronic energy characteristics of the chlorine adsorption process on the A type BCNT surface

\begin{tabular}{|c|c|c|c|}
\hline $\begin{array}{c}\text { Variant of } \\
\text { adsorption }\end{array}$ & Activation energy & Adsorption distance & Adsorption energy \\
\hline To center & 0.39 & 1.6 & -3.43 \\
\hline B-B & 0.37 & 1.9 & -4.58 \\
\hline
\end{tabular}

There is a high possibility for the adsorption of oxygen atom when the adsorbed atom is located above the $\mathrm{B}-\mathrm{B}$ bond for the $\mathrm{B}$ type $\mathrm{BCNT}$ and above $\mathrm{B}-\mathrm{C}$ bond for A type.

There is a high possibility of adsorption of chlorine atom when the absorbed atom is located above the B-B bond for the B type BCNT and above the hexagon center for the A type.

\section{References}

[1] Zaporotskova I.V. Carbon and Uncarbon nanomaterials and composite structures on their base: structure and electronic properties. Volgograd, VolGU, 2009, $490 \mathrm{p}$.

[2] Harris P. Carbon nanotubes and related structures: New materials for twenty-first century. oskow, Tehnosfera, 2003, 336 p.

[3] Lebedev N.G., Zaporotskova I.V., Chernozatonskii L.A. Fluorination of carbon nanotubes within molecular cluster method. Int. J. Quant. Chem., 2004, 100 (4), P. 548-558.

[4] Zaporotskova I.V., Perevalova E.V. Boron nanotubes: semi empirical investigation of structure and some physics and chemical properties. Tehnologia metallov, 2009, 9, P. 25-29.

[5] Boroznin S.V., Zaporotskova I.V., Perevalova E.V. About adsorption of molecular oxygen on the external surface of boron and boron-nitrogen nanotubes. Vestnik of Volgograd state university. Section 10: Innovation activity, 2011, 5, P. 18-25.

[6] McGuire K. Synthesis and Raman Characterization of Boron-Doped Single-Walled Carbon Nanotubes. arbon, 2005, 43, P. 219-227.

[7] Rubio A. Formation and electronic properties of $\mathrm{BC}_{3}$ single-wall nanotubes upon boron substitution of carbon nanotubes. Phys. Rev. B, 2004, 69, 245403.

[8] Zaporotskova I.V. , Boroznin S.V., Perevalova E.V., Polikarpov D.I. Electronic structure and characteristics of some types of boron containing nanotubes. Vestnik of Volgograd state university. Section 10: Innovation activity, 2012, 6, P. 81-86.

[9] Boroznin S.V. Intercalation of lights and transition metal atoms inside the nanotubes as a basis of nanowires. Fizika Volnovyh Processov i Radiotehnicheskie Sistemy, 2010, 13 (4), P. 87-95.

[10] Boroznin S.V., Prokofieva E.V., Zaporotskova N.P. Composites based on Carbon nanotubes Intercaleted with Atoms of Light and Transition Materials. Nanoscience \& Nanotechnology 2010. Book of abstract, 2010, P. 103-104.

[11] Zaporotskova I.V., Boroznin S.V., Boroznina E.V., Polikarpova N.P. Boron-carbon Nanotube Modification Using Alkaline Metal Atoms. J. Nano Electron. Phys., 2014, 6 (3), P. 03006(1-2).

[12] Boroznin, S.V.. Zaporotskova I.V., Perevalova E.V. Influence of metal superlattice to boron nanotube. Fundamental and Applied NanoElectroMagnetics (FANEM'12). Conf. Proc. Minsk. Belarus, 2012, 43 p.

[13] Zaporotskova I.V., Lebedev N.G., Chernozatonskii L.A. Electronic structure of carbon nanotubes modified by alkaline metal atoms. Phys. Solid State, 2004, 46 (6), P. 1174-1178.

[14] Zaporotskova I.V., Perevalova E.V., Boroznin S.V. Investigation of oxidation in boron-containing nanotubes. Nanosci. Nanotechnol. Lett., 2012, 4, P. 1096-1099. 